\title{
Ladislas Robert
}

Ladislas Robert (1924-2018) a été un membre très présent et très actif de la Société de Biologie et de ses instances dirigeantes pendant des années. Membre très fidèle et assidu de la Société de Biologie, il a été un animateur très écouté de nombreuses séances. Nous regrettons sa présence chaleureuse et ses interventions pertinentes.

Après son retour des États-Unis en 1962, Ladislas Robert a fait une longue carrière de chercheur au CNRS comme maître puis directeur de recherche. Il a été le directeur de la Fondation de Recherche sur le Tissu Conjonctif puis, de 1978 à 1994, le directeur du Laboratoire CNRS de Biochimie du Tissu Conjonctif à la Faculté de Médecine de Créteil (Val-deMarne).

Sur le plan médical et scientifique, Ladislas Robert a apporté des contributions de premier plan à la découverte et à la connaissance des glycoprotéines de structure de la matrice extracellulaire et a été à l'origine d'avancées décisives sur la compréhension du vieillissement.

Il a été membre actif de nombreuses sociétés savantes françaises, européennes, internationales, organisateur de nombreux colloques et réunions scientifiques, membre du comité de rédaction de plusieurs revues scientifiques, rédacteur et éditeur de nombreux ouvrages (les 11 volumes de «Frontiers of Matrix Biology», «Mécanismes cellulaires et moléculaires du vieillissement», «Les Horloges biologiques», «Le Vieillissement, de l'homme à la cellule», «Le vieillissement du cerveau : Parkinson, Alzheimer et autres démences», «Les Temps de la vie», «Les Secrets de la longévité », «Aging, facts and theories », ...). Il a créé en 1963, l'année suivant son retour des États-Unis, le Club Français du Tissu Conjonctif, devenu en 1982 la Société Française du Tissu Conjonctif (SFTC), société aujourd'hui dénommée Société Française de Biologie de la Matrice Extracellulaire (SFBMEc). Il a aussi créé en 1968, avec le Professeur John Scott de Manchester, la «Federation of European Connective Tissue Societies (FECTS) » dont le $50^{\mathrm{e}}$ anniversaire sera fêté à Manchester (Angleterre) en juillet au cours du congrès «Matrix Biology Europe 2018».

Son dynamisme n'avait pas faibli, jusqu'à son décès, car Ladislas Robert ne connaissait pas le mot retraite. Lorsqu'il est devenu directeur de recherche CNRS émérite et après trois déménagements, il a poursuivi son travail expérimental jusqu'en 2010 dans le laboratoire de recherche en Ophtalmologie à l'Hôtel-Dieu de Paris. Depuis 2010, il a encore rédigé plusieurs publications scientifiques et livres avec l'aide inestimable de son épouse, Jacqueline Labat-Robert.

Nous sommes bouleversés par le fait que Ladislas Robert soit décédé dans des conditions atroces, le 5 janvier 2018 à la suite de brûlures causées par l'incendie de sa maison. Son épouse, également une des nôtres, a subi un AVC dû au choc de cet évènement dramatique mais a survécu. 